\section{Questión}

Periodismo / Comunicación ISSN 1669-6581
- Av. $44 \mathrm{~N}^{\circ} 676,1^{\circ}$ piso

CP 1900 - La Plata - Argentina

www.perio.unlp.edu.ar/question

En las fronteras del conocimiento: lo lúdico como estrategia de socialidad

María Victoria Martin

DOI: https://doi.org/10.24215/16696581e315

\title{
En las fronteras del conocimiento: lo lúdico como estrategia de socialidad
}

\section{On knowledge's borders: playfulness as a sociality strategy}

María Victoria Martin / mvmartin@perio.unlp.edu.ar Instituto de Investigaciones Sociosimbólicas Latinoamericanas Aníbal Ford; Facultad de Periodismo y Comunicación Social; Universidad Nacional de La Plata/ Departamento de Ciencias Sociales - Universidad Nacional de Quilmes Docente investigador http://orcid.org/0000-0001-6249-6935

Resumen

La mayoría de nosotros, probablemente podamos en un período más o menos corto y vacuna mediante, inmunizarnos frente al COVID-19 y regresar a las aulas, pero salir de la virtualización de las relaciones nos llevará mucho más tiempo, si es que acaso lo logremos. En este trabajo, reflexionamos y relatamos la experiencia llevada adelante para favorecer la socialidad entre estudiantes, y entre estes y les docentes, mediante la creación de espacios lúdicos incluidos en las aulas virtuales de asignaturas de distinto nivel.

Palabras clave: plataformas educativas- socialidad- juego

\section{Abstract}

Sooner or later, and thank to the COVID-19 virus vaccine, most of us will be probably able to return to classrooms but leaving the virtualization of relationships will take much longer. In this article we reflect and account the experience carried out through recreational spaces included in 
the virtual classrooms of subjects of different levels that aimed to promote relationships among students and also, between them and teachers.

Keywords: virtual educational platforms- sociality- playfulness

\section{Algoritmos y cuarentena}

Esta pandemia deja visible de qué manera el capitalismo, y en especial el neoliberalismo, han ido configurando, en términos de efectos, una serie de horizontes o expectativas de los hombres y mujeres de gran parte del planeta. No escapamos quienes habitamos o formamos parte de las instituciones educativas respecto de lo que es - o debería ser- el propósito de las mismas. Aunque no son objeto de esta reflexión, ocurre algo similar en tantos otros ámbitos, como muchos de los ámbitos laborales vinculados con la administración, profesiones liberales o, peor aún, de los servicios característicos del capitalismo de plataformas, como los ofrecidos mediante Glovo, Rappi, PedidosYa, Airbnb o Uber (en donde el capital lo ponen aquellos que pedalean, hospedan o manejan y el beneficio queda en manos de los dueños de los servidores que los ofrecen, quienes acumulan los datos de los que los contratan sin tener ningún bien más que la plataforma de enlace).

Nick Srnicek define a la "economía digital", como "aquellos oficios que dependen cada vez más de la tecnología de información, datos e internet para sus modelos de socios" (2018, p.12). En este contexto, de virtualización de clases, nos preguntamos ¿qué ocurre cuándo queda en evidencia que la enseñanza y el aprendizaje ingresan y se configuran en una suerte de economía del conocimiento?

Un primer punto, está relacionado con un escenario que Esther Díaz describió como "proyectos digitales y realidades analógicas". Más allá de los altos índices de penetración de dispositivos entre la población argentina, que configuran escenarios de alta disposición tecnológica en varios segmentos de la población, y los acuerdos de la ENACCOM para que las compañías de telefonía celular no consuman datos en el uso de los dominios educativos, la brecha digital resulta innegable. La discontinuidad del Programa Conectar Igualdad durante todo el período de la administración de Mauricio Macri, hizo estragos en los estratos más vulnerables. No obstante, esta desigualdad está siendo abordada y visibilizada por múltiples voces y organizaciones, por lo que no es objeto de estas líneas. 
A lo que queremos referirnos es a una suerte de retorno a los saberes como eje de la educación. Es cierto que estos ya no se limitan al libro escrito o al docente y que necesariamente habilitan recurrir a otros nodos de información y conocimiento, como videos de Youtube, consulta a fuentes digitales de diversos tipos y calidades, en gran parte de los casos. Pero parecería ser que, en función de cumplir con los contenidos y el programa de la materia, la relación pedagógica se vacía, en pos de un conocimiento que se vuelve mercancía preciada $y$, en el contexto de confinamiento social, resulta imposible disimular aquello que ocurre en la mayoría de las clases presenciales: el lugar secundario y empobrecido que queda para entretejer vínculos sociales. En las aulas presenciales, el encuentro cara a cara, a veces multitudinario, disimula a la perfección que el mero hecho de estar reunidos no garantiza ningún tipo de comunidad. En definitiva, consecuencia del liberalismo, ya veníamos de una hiperinidividualización de los sujetos y sus prácticas, más relacionados con dispositivos tecnológicos que con el mundo circundante.

Esta situación inédita de aislamiento borra las fronteras entre lo público y lo privado. Si público significa "abierto", "disponible al público", entonces hace referencia a aquello que resulta visible u observable, lo que se expone a muchos, lo que debe ser informado. En oposición, lo privado, alude a lo que queda oculto a la mirada, lo dicho o realizado en privacidad o en secreto dentro de un grupo de personas. En las situaciones de teletrabajo, enseñanza y aprendizaje incluidas, ese orden se ve modificado y se superponen los planos. "Los límites espaciales del hogar y de las demás instituciones, se ven permeados y atravesados de manera discrecional por las comunicaciones vehiculizadas por dispositivos que no necesitan anclaje territorial. Si bien aparecerían en principio como potenciadoras de relaciones en redes más flexibles en todo sentido (espacio, tiempo, instituciones y roles), esto va a diferir de acuerdo con el contexto social general". (Martin, 2011, p.355)

Georg Simmel (1986) caracterizaba a las sociedades modernas como aquellas integradas por individuos que combinan una multitud de roles diferentes, y cuya individualización crecía en la medida que cada persona configuraba su propio establecimiento de rol y con una trayectoria cambiante en el tiempo. Al brindar la posibilidad de cambiar de roles y hacerlos flexibles sin moverse de un lugar, los dispositivos para el teletrabajo parecen armonizar distintas obligaciones, ya que aquellos roles diacrónicos, hoy pueden ejercerse de manera sincrónica. Es claro el caso de docentes que deben preparar clases y responder consultas en 
videoconferencias, con sus hijos dando vueltas o jugando por detrás; o el hecho de tener que combinar en un mismo espacio y lugar el rol docente con el de padre/madre; y lo mismo sucede con los y las estudiantes.

Además, ya advertía Giddens sobre el desenclave de las instituciones modernas, es decir a "la extracción de las relaciones sociales de sus circunstancias locales y su rearticulación en regiones espaciotemporales indefinidas" (Giddens, 1995, p.34). Este salirse de las instituciones provocado por la situación de distanciamiento social, está menos vinculado a "la tecnología, sino el desarrollo de las redes de sociabilidad basadas en la elección y la afinidad, rompiendo las barreras organizativas y de espacio en las relaciones. El resultado social de estas redes es doble: por un lado, desde el punto de vista de cada individuo, su mundo social se forma alrededor de sus redes, y se desarrolla con la composición de la red; por otro lado, desde el punto de vista de la red, su configuración opera como punto de referencia de cada uno de los que participan en la misma" (Castells et al, 2007, p.229).

Cómo se ha indicado varias veces en este último mes, lo público, nuestra fase relacionada con la actividad que realizamos en instituciones para otros, nos ha invadido casi sin límites y en una rutina que ahoga las 24 horas de los 7 días de la semana a través de cuanto dispositivo de conectividad sea posible, en nuestros hogares y en nuestro tiempo libre, en nuestros vínculos personales y familiares, en nuestra intimidad de las pantuflas y el pijama, pero también en nuestros sentires y pesares, en nuestra subjetividad tan cambiante como montaña rusa.

Recuperando una idea de Jaques Ellul coincidimos en que "la Técnica es, de hecho, el medio ambiente del hombre. Estas mediaciones se han generalizado, extendido, multiplicado de tal modo que han terminado por constituir un nuevo universo. Hemos visto aparecer el 'medio técnico'. Eso quiere decir que el hombre ha dejado de estar en el medio 'natural' (constituido por eso que llamamos vulgarmente la naturaleza, campo, bosque, montaña, mar, etcétera) en primer lugar, para situarse en la actualidad en un nuevo medio artificial." (Sadin, 2017, p.43). En esta situación excepcional que nos toca vivir, todo ha sido vorágine y, en muchos casos, improvisación. Ellul agrega que "un grupo humano busca 'perseverar en el ser', sólo adopta las innovaciones progresivamente y tiende a absorberlas: sin embargo, hemos visto que la relación se ha invertido. Ahora, es la técnica la que engloba y determina las formas culturales, la civilización" (Sadin, 2017, p.55). Resalto: PROGRESIVAMENTE, para perseverar en el ser... ¿qué ocurre con nuestro ser cuando el medio técnico, incluso aquellos dispositivos a los que 
estamos acostumbrados se nos imponen sin pausa alguna y se cuelan en cada rincón de nuestras prácticas cotidianas y laborales?

La virtualización más o menos abrupta de las clases presenciales deja en claro situaciones y configuración de relaciones pedagógicas y no pedagógicas que de hecho se dan en los encuentros cara a cara en las aulas: la socialidad entre pares y con docentes; no hay nada nuevo, sino que quedan al descubierto. Tal como la define Martín-Barbero (2000) la socialidad refiere a "la trama de relaciones cotidianas que tejen las gentes al juntarse y en la que anclan los procesos primarios de interpelación y constitución de los sujetos y las identidades". En otras palabras: en muchas ocasiones, el encuentro más o menos puntual con cierta frecuencia estipulada, se ha convertido en un medio técnico, en el que cada quien está enchufado con su propio mundo e intereses a través de la pantallita de su teléfono móvil, en la mayoría de los casos solo conectándose con sus compañeros de clase en la medida en que son directamente interpelados. Como si nos hubiésemos olvidado que "habitar un territorio es convivirlo [...]. E intervenir en su transformación humana: participar. En este sentido, participar significa vivir y relacionarse de un modo diferente" (Saravia Madrigal, 2004).

La construcción de comunidad

Francesco Tonucci recuerda que "Ios niños sienten mucho la falta de la escuela, es decir, no de los profesores y los pupitres sino la falta de los compañeros. La escuela era el lugar donde los niños podían encontrarse con otros niños". Algo similar ocurre con los jóvenes: los bares, boliches, clubes, las esquinas y plazas, junto con otros espacios públicos simplemente, dejaron de funcionar; pero la escuela y la universidad, siguen activas y también son lugares donde pueden encontrarse con sus pares. Y, por qué no decirlo, también con los adultos.

En la vorágine tecnológica en que hemos sido sumidos, nunca resultó más cierto que las TIC se erigen como lugar preponderante de mediación, esto es, de configuración de sentidos hegemónicos, usualmente generando una suerte de "despoder social" en torno al conocimiento y la participación en procesos de producción de información, desplazando a otras mediaciones más próximas territorialmente como el Estado, la escuela y la familia: "la (mediación) tecnológica adquiere una importancia quizás desmedida, al tiempo que otras mediaciones casi desaparecen, o sea trinchera en fundamentalismos desde donde buscan tener alguna 
oportunidad de incidencia en el intercambio social en su conjunto" (Orozco Gómez, 2002, pp. 26-27).

No siempre el hogar resulta un lugar propicio para concentrarse y "aprovechar el tiempo" y, la incertidumbre del afuera y del futuro, definitivamente, no colaboran con los propósitos de construir conocimientos a cualquier costo. Como dice Alexandra Cohan (2020), "rápidamente entendimos que para leer no se requiere solamente tiempo, sino toda una disposición que, según creo, tiene que ver con silenciar el mundo, silenciar sus demandas y habitar la soledad como refugio, aislarnos del mundo mientras el mundo sigue funcionando. Hoy es al revés: el mundo nos silenció a nosotros, el mundo se detuvo y nosotros quedamos pedaleando en el aire. Somos muchos los que no pudiendo leer porque resulta insoportable sustraerse de lo poco que hay ahí "afuera" de nosotros. Estamos aislados literalmente, no sé cómo se podría leer en estas circunstancias".

En este contexto, no sabemos cuáles son las posibilidades tecnológicas ni las capacidades intelectuales, ni los condicionamientos psicológicos y subjetivos de nuestros estudiantes, apenas si podríamos llegar a arriesgar sobre los nuestros, pero sí debemos tener en claro que la función primera hoy debería ser la de contener y contenernos, para no perder de vista que cada clase e institución educativa, conforma, antes que nada, una comunidad. Compartimos la idea de Zygmunt Bauman: "un lugar cálido, un lugar acogedor y confortable. Es como un tejido, bajo el cual cobijarse cuando llueve mucho como una fogata ante la que calentar nuestras manos en un día helado (...) en el que no hay rincones (...), nos entendemos bien, podemos confiar en lo que oímos, estamos seguros la mayor parte del tiempo y rarísima vez sufrimos perplejidades o sobresaltos (...) podemos contar con la buena voluntad mutua." (2003, pp. 810).

Y, aún más, agrega, casi de modo premonitorio: "nosotros, que vivimos en tiempos despiadados, en tiempos de rivalidad y competencia sin tregua, cuando la gente nos rodea parece ocultarnos cartas y pocas personas parecen tener prisa alguna por ayudarnos, cuando en contestación a nuestros gritos de auxilio escuchamos exhortaciones ayudarnos a nosotros mismos..." (Bauman, 2003, p.10).

En esta línea, debemos estar atentos y no romantizar la idea de quedarnos en casa, he escuchado a docentes más que optimistas sobre la situación decir que "todo depende de uno mismo, de las ganas o el esfuerzo que pongamos", "es un tema de actitud", compartiendo 
aplausos de profesores jubilados o aconsejando sobre los beneficios de la eutonía, en lugar de escuchar y atender demandas hechas por colegas que trabajan a destajo y que no pueden continuar haciendo como si nada ocurriese, porque registran lo que (les) ocurre a ellos y a muchos de sus estudiantes. Encontramos ahí los frutos de la piscología positiva que, en su versión más coloquial argumenta que "cualquiera puede reinventar su vida y convertirse en la mejor versión de sí mismo simplemente adoptando una visión más positiva de su yo y del mundo que lo rodea" (Cabanas e Illouz, 2019, p.4). Sin embargo, los autores advierten que detrás de esas "promesas de autorrealización, crecimiento personal y mejora social, tanto en la teoría como en la práctica, parecía comportarse más como el brazo académico de la ideología neoliberal y del capitalismo de consumo que como la ciencia neutral y objetiva sobre el bienestar humano que afirmaba ser". (ibídem).

A su vez, en su crítica respecto a la felicidad como algo que depende exclusivamente de uno mismo, sentencian: "hace falta una esperanza crítica, fundamentada en razones, en la justicia social y en la acción colectiva; una esperanza que no sea paternalista, que no decida por nosotros lo que es bueno para nosotros, que no pretenda protegernos de lo peor a base de enseñarnos a negarlo, sino que nos coloque en una mejor posición para hacerle frente y cambiarlo. Y no como individuos aislados, sino juntos, como sociedad. El mundo interior no es un lugar en el que queramos vivir. Tampoco es el lugar desde el que podamos conseguir ningún tipo de cambio social significativo" (2019, p.95).

La virtualidad, lo lúdico y la comunidad

Edward Sadin, dedica un apartado de su libro La humanidad aumentada a la dimensión lúdica de la tecnología. Se refiere a los dispositivos electrónicos, en especial los destinados usos privados y cotidianos, a los que se otorga un lugar dicotómico respecto de la "orientación que adopta respecto del trabajo" (2017, p.94), ya sea como posibilidad de liberación o, por el contrario, como fuerza alienante.

Jugar contribuye a un crecimiento sano, nos permite expresar emociones y a elaborar situaciones negativas y traumáticas y a la autorregulación emocional (a través de un meme, un chiste o una canción, por ejemplo), pero lo que nos interesa, es que el juego nos permite afianzar los vínculos entre las personas con quienes jugamos; y a desarrollar la autoconfianza; entre otros. 
En el juego se vivencian emociones y tensiones que reconfiguran los modos de jugar y a veces sus reglas. Entonces, podemos pensar la importancia del juego en tanto saber jugar, pero también el juego como saber. "La relevancia pedagógica del juego radica en brindar la posibilidad de ocupar distintos roles: ser partícipe del juego o gestor del mismo, motivando así el rol activo frente al conocimiento, a la construcción de las reglas, y a la construcción del sentido del mundo desde lo simbólico, pero también desde lo real. Por este motivo, podemos pensar al juego desde una dimensión superficial, la lúdica pero también desde otra dimensión profunda, la construcción de subjetividad. Esta distinción entre superficial y profundo no responde a valoraciones, sino a lo que aparece a primera vista y a lo que se encuentra un tanto más oculto" (Martin, Díaz Larrañaga y Zapatería, 2018, p.8).

Sabemos, además que los espacios públicos virtuales "facilitan las relaciones sociales — de intensidad y calidad relativas - y serán ellos reconocibles por "la fuerza mixturante de grupos y comportamientos y por su capacidad de estimular la identificación simbólica, la expresión y la integración culturales" (Borja, 1998, pp. 25-45).

Cuando empezó la cuarentena, intuíamos que mis hijas en edad de Primaria, extrañaban a sus compañeros, los juegos, los recreos, el estar con otros (incluso siendo hermanas de edades similares). Habían tenido contacto con sus amigos y docentes solo 4 días en lo que iba del ciclo lectivo. Dispuestos a darle batalla a la situación, inventamos desafíos para que los otros niños y niñas de sus grados pudieran participar y mantener los vínculos, no uno a uno, sino entre todos. Comenzamos con una fiesta de disfraces: una o dos fotos por familia subidas el viernes entre las 19 y las 20; luego fue la construcción de bigotes caseros, también con fotos y otra familia propuso hacer una bicicleta humana (solo respondimos nosotros). De la mitad del grupo participando al comienzo, quedaron 3 ó 4 en el mejor de los casos hasta que la pijamada tuvo una sola respuesta de entre 60 familias.

En ese momento, ya estaban en marcha las propuestas lúdicas para mis propios estudiantes: no quería dejar librado al azar los vínculos entre ellos. En los cursos de secundario, había estudiantes nuevos que se habían visto solo 3 jornadas con sus pares; en la Universidad, suelen ser pocos quienes se conocen en las materias del ciclo superior, porque eligen las asignaturas en función de sus intereses, horarios y la voluntad del SIU guaraní que les permite, o no, encontrar cupo. 
Considerando lo anterior, sumado al hecho de pensar que algunos de los estudiantes podrían estar o sentirse solos durante el confinamiento obligatorio, alejados de sus pares, habilitamos en las aulas virtuales a cargo espacio de juego, denominados "Zona de recreo", para el nivel secundario y "BAR Abierto y libre de COVID-19" en el grado universitario. Lo que se buscaba era generar relaciones de socialidad entre los mismos estudiantes y entre éstos y los docentes, que no estuvieran atravesadas por el conocimiento. Así, planteábamos cierta horizontalidad en las relaciones, incluso pidiendo que los mismos alumnos y alumnas propusieran alguna de las consignas de juego.

Las propuestas son variadas e incluyen compartir, memes, selfies; coincidiendo con Pascuas y Pesaj, se pidieron antipublicidades sobre esa conmemoración; identificar bandas de rock dibujadas en una imagen; realizar un gift animados; pedir canciones bailables en idiomas incomprensibles, formularios para hacer radiografías de los gustos y actividades del tiempo libre (música, películas, series, libros, youtubers, mascotas, deportes, etc.), records guinness bizarros, el mejor insulto de serie o película, aforismos incomprensibles, entre otros. A las dos semanas se da por finalizado cada juego y se borra, para eliminar datos innecesarios, pero, sobre todo, para que fueran simplemente experiencias de contacto y permitirles reconfigurarlos en su memoria. Descontando las actividades con carácter obligatorio, fue el espacio más concurrido y en el que participaban con mayor rapidezi.

Como apunta Bauman, la palabra comunidad tiene un dulce sonido porque" evoca lo que no genera nostalgia y lo que "nos falta para tener seguridad, aplomo y confianza" (2003, p.10.) En esos espacios de juego, y para no quedar pedaleando en el aire, intentamos habilitar la oportunidad de ser más que estudiantes y docentes entramados respecto del saber, que nos permitiera abrazarnos en otras dimensiones constitutivas de lo humano y que siguen siendo una necesidad, tanto en las aulas virtuales como en las presenciales.

Bibliografía

Bauman, Z. (2003). Comunidad. En busca de seguridad en un mundo hostil. Madrid, España, Siglo XXI

Borja, Jordi (1998), “Ciudadanía y Espacio público”, Revista del CLAD (Centro Latinoamericano de Administración para el Desarrollo) Reforma y Democracia, N. ${ }^{\circ} 12,1998$, pp. 25-45. 
Cabanas, E. e Illouz, E. (2019). Happycracia. Cómo la ciencia y la industria de la felicidad controlan nuestras vidas. Barcelona, Paidós.

Castells, M. y otros (2007), Comunicación móvil y sociedad, una perspectiva global. España, Fundación Telefónica- Ariel. Versión en castellano: Ariel - Fundación Telefónica [En línea] www.eumed.net/libros. Acceso: 23/09/2010.

Giddens, Anthony. (1995). Modernidad e identidad del yo. El yo y la sociedad en la época contemporánea. Barcelona, Península.

Kohan, A. (2020). "El mundo se detuvo y quedamos pedaleando en el aire". Revista Mate, abril, CABA. En línea: https://www.revistamate.com.ar/

Losada, A.V. (2020). "Cuando jugar es cosa seria". En Actualidad Psicológica, AÑO XLV - № 494, abril, CABA. En línea: https://es.scribd.com/document/316007061/Revista-ActualidadPsicologica-N\%C2\%BA-494

Martin, M.V, Díaz Larrañaga, N. y Zapatería, M. (2018). "Juego, derechos y ciudadanía: la ludoteca como ámbito de intervención social". Question, 1(58), e040. La Plata, FPyCS-UNLP. Martin, M.V. (2011) "Ni público ni privado: la telefonía celular y la personalización del espacio", en: Chardon, M. C. (comp.). Transformaciones del espacio público. Los actores, las prácticas, las representaciones. Buenos Aires, La Crujía Ediciones.

Orozco Gómez, G. (2002). "Mediaciones tecnológicas y des-ordenamientos comunicacionales". Signo y Pensamiento, vol. XXI, núm. 41, Colombia, Pontificia Universidad Javeriana Bogotá.

Sadin, E. (2017). La humanidad aumentada. Buenos Aires, Caja negra.

Saravia Madrigal, M. (2004). "El significado de habitar", de la página Ciudades para un futuro más sostenible de la UPM. En Línea: http://habitat.aq.upm.es/. Acceso: 01/11/2009

Simmel, Georg (1986) "Conflicto y la red de afiliaciones de grupo", en Sociología: Estudio de las formas de socialización. Madrid, Alianza Universidad. 1르 edición, 1908.

Srnicek, N. (2018). Capitalismo de plataformas, Buenos Aires, Caja Negra.

Tonucci, F. (2020). "No perdamos este tiempo precioso dando deberes", Diario El País, marzo, Madrid. En línea: https://elpais.com/

Nota 


\begin{abstract}
' A punto de entregar este texto, el mismo día del envío, la Escuela Graduada Joaquín V. González perteneciente a UNLP, habilitó un (mural colaborativo llamado "Encuentros en tiempos de cuarentena", pensado para que "a pesar de la distancia, nos sintamos más cerca" en el que enlazaban otros murales en donde las chicas y chicos que asisten al nivel primario puedan intercambiar experiencias por fuera de lo estrictamente pedagógico: juegos y experiencias en familia; recomendaciones de libros, películas y series; recetas de cocina; música; pasatiempos y arte. Al tratarse de menores, un administrador habilita los aportes.
\end{abstract}

